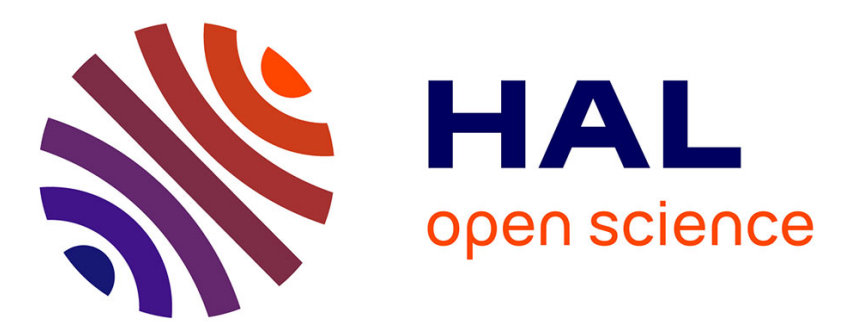

\title{
Heavy Metal Determination in Atmospheric Deposition and Other Fluxes in Northern France Agrosystems
}

\author{
Sam Azimi, Philippe Cambier, Isabelle Lecuyer, Daniel R. Thevenot
}

\section{To cite this version:}

Sam Azimi, Philippe Cambier, Isabelle Lecuyer, Daniel R. Thevenot. Heavy Metal Determination in Atmospheric Deposition and Other Fluxes in Northern France Agrosystems. Water, Air, and Soil Pollution, 2004, 157, pp.295 - 313. 10.1023/B:WATE.0000038903.25700.5a . hal-01087407

\section{HAL Id: hal-01087407 https: / hal-enpc.archives-ouvertes.fr/hal-01087407}

Submitted on 26 Nov 2014

HAL is a multi-disciplinary open access archive for the deposit and dissemination of scientific research documents, whether they are published or not. The documents may come from teaching and research institutions in France or abroad, or from public or private research centers.
L'archive ouverte pluridisciplinaire HAL, est destinée au dépôt et à la diffusion de documents scientifiques de niveau recherche, publiés ou non, émanant des établissements d'enseignement et de recherche français ou étrangers, des laboratoires publics ou privés. 


\title{
HEAVY METAL DETERMINATION IN ATMOSPHERIC DEPOSITION AND OTHER FLUXES IN NORTHERN FRANCE AGROSYSTEMS
}

\author{
SAM AZIMI $^{1}$, PHILIPPE CAMBIER $^{2, *}$, ISABELLE LECUYER $^{2}$ \\ and DANIEL THEVENOT ${ }^{1}$ \\ ${ }^{1}$ Centre d'Enseignement et de Recherche sur l'Eau la Ville et l'Environnement (Cereve), UMR \\ MENRT-MAP 99022 101, Université Paris XII-Val de Marne, Faculté de Sciences et Technologie, \\ 61 Avenue du Général de Gaulle, F-94010 Créteil Cedex, France, ${ }^{2}$ Unité de Science du Sol, Institut \\ National de la Recherche Agronomique (INRA), Route de St. Cyr, F-78 026 Versailles Cedex, France \\ ( ${ }^{*}$ author for correspondence, e-mail: cambier@versailles.inra.fr, Fax: +33-1-30-83-32-59, \\ Tel: +33-1-30-83-32-36)
}

(Received 1 July 2003; accepted 24 March 2004)

\begin{abstract}
The aim of this study is to assess the annual balance of the fluxes of $\mathrm{Cd}, \mathrm{Cu}, \mathrm{Ni}, \mathrm{Pb}$ and $\mathrm{Zn}$ within different cropping systems, in an experimental site located near Versailles, France. Four fluxes through the cultivated horizon were considered to assess the annual heavy metal balance in these systems: 1) atmospheric depositions, 2) fertilisers as inputs, 3) crops and 4) leaching water as outputs. The water mass flow was estimated with a model (CERES) while the other parameters were actually measured through field sampling. Some large uncertainties are related to analytical detection limits, specially for $\mathrm{Pb}$ which presents very low concentrations in nitrogen fertilisers, in crops and in soil solution. Cd was also close to the detection limits in atmospheric deposition and in soil water, and $\mathrm{Zn}$ could not be analysed in soil solution. Nevertheless, the following trends clearly appeared: firstly, atmospheric deposition is the major input way of $\mathrm{Cu}, \mathrm{Ni}, \mathrm{Pb}$ and $\mathrm{Zn}$ in the soil, whatever the cropping system, whereas $\mathrm{Cd}$ is introduced mainly by fertilisers. Secondly, the uptake of heavy metal by wheat is generally larger than by a pea culture, except for Ni. Finally, the global pattern shows an accumulation of $\mathrm{Cd}, \mathrm{Ni}$ and $\mathrm{Pb}$ in the cultivated horizon while $\mathrm{Cu}$ decreased. The annual balances, during the cropping year 2001-2002, represented about $0.33,-0.024,0.014$ and $0.014 \%$ of the actual stocks in the cultivated horizon, of $\mathrm{Cd}, \mathrm{Cu}, \mathrm{Ni}$, and $\mathrm{Pb}$, respectively.
\end{abstract}

Keywords: accumulation, balance, $\mathrm{Cd}$, crop uptake, $\mathrm{Cu}$, cultivated horizon, fertilisers, $\mathrm{Ni}, \mathrm{Pb}$, trace elements, $\mathrm{Zn}$

\section{Introduction}

The contamination of soil and agrosystems by heavy metals affects the health of soil-plant ecosystems. Such pollution also affects the human being through the contamination of the food chain. At a local-scale, many areas in Europe have been severely contaminated by industrial emissions or by hazardous applications of wastes on fields. At a large scale, atmospheric pollution has been recognised as an important heavy metal source for soils, with historical maximum loads around the 1970-1980s in the case of lead (Lobinski, 1995; Weiss et al., 1999). Another source of large-scale contamination of cultivated soils is the use of common amendments and fertilisers. Indeed, some phosphate fertilisers and organic manures have

Water, Air, and Soil Pollution 157: 295-313, 2004.

(C) 2004 Kluwer Academic Publishers. Printed in the Netherlands. 
been well established as sources of heavy metals (Jones et al., 1987; Jones et al., 1987; Juste and Robert, 2000; Juste and Tauzin, 1986; Mench, 1998). These potential sources, both from large and local scales, associated with natural outputs (leaching water, run-off) and crop uptake contribute to the heavy metal balance in cultivated soils (Hovmand, 1984). Nevertheless, the atmospheric depositions were decreased during the last decade (Azimi et al., 2003; Lawlor and Tipping, 2003). Therefore, the balance of heavy metals in agrosystems remains a debated issue, related to the determination of critical loads from atmospheric pollution (Brus et al., 2002; De Vries and Bakker, 1996) or to the recycling of urban waste (Bartl et al., 2002).

However, the data needed for the determination of all fluxes and balances in agrosystems are not easily measurable. Indeed, Brus et al. (2002) compared the Cd concentrations in soils expected from different reported fluxes and the estimated critical $\mathrm{Cd}$ concentration by modelling soil-water-plant transfers. Moolenar and Lexmond (1998) directly measured most of the fluxes of $\mathrm{Cd}, \mathrm{Cu}, \mathrm{Pb}$, and $\mathrm{Zn}$ in agrosystems of the Netherlands at the 'farm-gate' scale and at field scale but used a model and laboratory adsorption experiments to evaluate the outputs by leaching. Keller et al. (2001) also used several models to estimate heavy metal fluxes from agricultural statistics at a regional scale. Moolenar and Lexmond (1998) as well as Keller et al. (2001) pointed out 1) the relative importance of atmospheric deposition for $\mathrm{Pb}$ inputs in arable-land systems and 2) the importance of fertilisers and farming systems for the balances of $\mathrm{Cd}, \mathrm{Cu}$ and $\mathrm{Zn}$. Both studies differentiated arable-land, animal husbandry and mixed-farm systems, the latter appearing more sustainable with respect to heavy metal accumulation (Moolenaar and Lexmond, 1998).

The aim of the present study is to provide a detailed analysis of the fluxes of heavy metals $(\mathrm{Cd}, \mathrm{Cu}, \mathrm{Pb}, \mathrm{Ni}$ and $\mathrm{Zn})$ through a site representative of Northern France agrosystems, and compare the different cropping systems which are used on it. To reach this goal, element fluxes coming from diffuse sources, i.e., agricultural inputs and long-range atmospheric pollution as well as output fluxes, i.e., crops and leaching water, were measured on an experimental site devoted to develop and compare cultivation systems.

\section{Materials and Methods}

\subsection{EXPERIMENTAL SITE}

Samples were taken from the site 'La Cage', an experimental field of 12 ha which has been used for several decades by the French national institute of agronomic research (INRA), in a representative way of intensive cereal production. This site is located near Versailles, $15 \mathrm{~km}$ west from Paris (France) on a typical silt loam soil of Northern France. Table I resumes the characteristics of the cultivated horizon from samples collected in 1998, when a new long-term experimentation started, to develop, test 
TABLE I

Main soil characteristics in 1998 at the beginning of the Sustainable and Integrated Cultivation System (SICS) experimentation (mean \pm standard deviations of 12 samples at $0-25 \mathrm{~cm}$ depth)

\begin{tabular}{llllll}
\hline Clay content & Silt & Sand & C orga. & C/N & pH in water \\
$16.7 \pm 0.7 \%$ & $58.4 \pm 6.6 \%$ & $24.9 \pm 7.2 \%$ & $0.96 \pm 0.12 \%$ & $9.94 \pm 0.16$ & $7.33 \pm 0.21$ \\
\hline CEC & {$[\mathrm{Fe}]_{\text {total }}$} & {$[\mathrm{Mn}]$} & {$[\mathrm{Cd}]$} & {$[\mathrm{Pb}]$} & {$[\mathrm{Zn}]$} \\
$111 \pm 7$ & $16855 \pm 1435$ & $511 \pm 64$ & $0.233 \pm 0.020$ & $44.3 \pm 10.0$ & $55.0 \pm 6.0$ \\
\hline
\end{tabular}

$\mathrm{CEC}=$ Cation Exchange Capacity in $\mathrm{mmol} . \mathrm{kg}^{-1}$; metal concentrations are given in $\mathrm{mg} . \mathrm{kg}^{-1}$ dry weight.

and compare alternative cultivation systems (Sustainable and Integrated Cultivation Systems program, SICS). These systems are not defined by constant procedures but by different sets of decision rules. They are: 1 ) a productive system (PRO), aiming to get the maximum potential yield, which is used as a reference; 2) an integrated system (IN), aiming both to preserve the economic profitability and to limit the environmental impacts and 3) an organic system (ORG), following the French charter for organic agriculture, and a system with no soil tillage which will not be considered in the present study. These cultivation systems were applied on plots of $11200 \mathrm{~m}^{2}$ each, divided in two parts for a rotation. Every year, one part is used for wheat and the other part is used for another culture (Figure 1). A buffer zone with fallow or a reference culture surrounds each cultivation system in order to avoid treatment drifts and border effects.

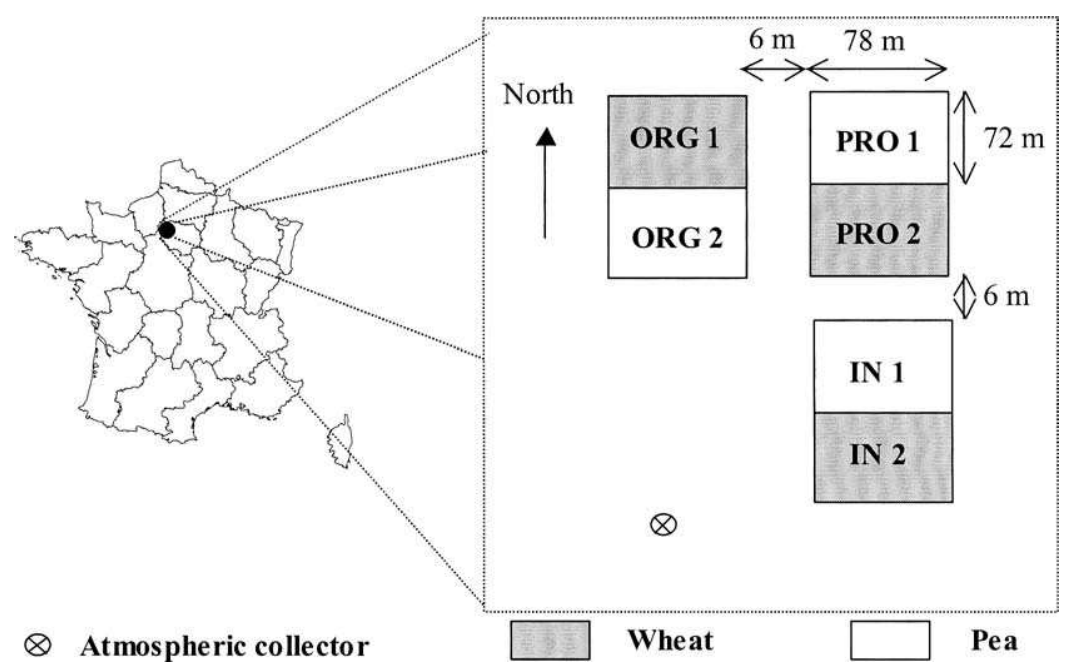

Figure 1. Place of wheat and pea following each cultivation systems: productive (PRO), integrated (IN) and organic (ORG) of the experimental site of Versailles (France). 


\subsection{INPUT/OUTPUT FLUXES CONSIDERED}

The fluxes which are considered are those passing through the limits of the cultivated horizon $(0-30 \mathrm{~cm})$ at an annual time scale. The input fluxes concern the atmospheric depositions, the seeds, the fertilisers and the pesticides. The output fluxes are due to crops and leaching water. Other fluxes can be identified: lateral fluxes caused by lateral leaching, surface run-off, and earth displacement (Juste and Mench, 1992). They were all neglected in the present work because studied plots were large and uniformly flat. Another flux corresponds to the uptake of elements by deep roots (deeper than $30 \mathrm{~cm}$ ) from soil sub-layers towards other roots or plant shoots. But the density of roots in the cultivated horizon is generally much higher than in deeper layers (Barber, 1995). Gaseous fluxes could be of concern for elements like mercury or selenium. These three types of fluxes were neglected in the present study dealing with $\mathrm{Cd}, \mathrm{Cu}, \mathrm{Ni}, \mathrm{Pb}$ and $\mathrm{Zn}$.

Except for the leaching water, all the considered fluxes were measured at the 'La Cage' site. Indeed, the water mass flow corresponding to leaching has been calculated using the model (CERES). This model simulates the growth of cultivated plants and water, $\mathrm{N}$ and $\mathrm{C}$ cycles in various soil-crop systems (Gabrielle et al., 1995; Jones and Kiniry, 1986). The input data used by the model were of three kinds:

- Daily meteorological data (temperature, radiation, precipitation, potential evapotranspiration);

- Soil characteristics given by layers at a decimetric scale, down to $120 \mathrm{~cm}$ (texture, organic matter, bulk density, hydraulic conductivity, field retention capacity);

- Agronomic and physiologic data: date and seeding density, plant characteristics, nitrogen inputs, mass and $\mathrm{C} / \mathrm{N}$ ratio of plant residues after harvesting, etc.

The hydraulic part of the model, which takes into account only vertical flows, has been validated on a soil similar to the one investigated in this study (Gabrielle et al., 1995).

\subsection{SAMPLING}

Atmospheric deposition. The total atmospheric deposition (TD) collection integrating both dry and wet deposition was performed using a system made with a high density polyethylene (HDPE) bottle $(5 \mathrm{~L})$ connected to a Teflon funnel of $113 \mathrm{~cm}^{2}$ collection area. All this equipment was placed inside a PVC pipe with PVC needles on top to avoid bird nesting. Collector heights reached $190 \mathrm{~cm}$ to avoid the collection of re-suspended soil particles (Azimi et al., 2003). The sampling period of TD was 7 days from 1 October 2001 to 22 November 2002.

Seeds. They were stored in their commercial bags for the purpose of the SICS research program. Samples of a few hundred grams were randomly grabbed from one bag corresponding to each kind of seed and kept in new plastic containers for 
TABLE II

Annual fertiliser loads ( $\mathrm{kg} \mathrm{ha}^{-1}$ per year) from 1999 to 2002. Horizontal arrows display the cultivation period

\begin{tabular}{|c|c|c|c|c|c|c|c|c|c|c|c|}
\hline & \multirow[b]{2}{*}{1999} & \multirow[b]{2}{*}{2000} & \multirow[b]{2}{*}{2001} & \multicolumn{2}{|c|}{2001} & \multicolumn{5}{|c|}{2002} & \multirow{2}{*}{$\begin{array}{l}\text { Total annual } \\
\text { flow }\left(\mathrm{kg} \cdot \mathrm{ha}^{-1}\right)\end{array}$} \\
\hline & & & & Sept & Oct & Feb & Mar & Apr & May & Jun Jul & \\
\hline $\mathrm{IN}-1$ & wheat & colza & wheat & & & & & & & & IN pea \\
\hline $\mathrm{N}$ & 465 & 520 & 600 & & & & & & & & 0 \\
\hline $\mathrm{MgS}$ & & 100 & & & & & & & pea & & 0 \\
\hline PK & & & & 200 & & & & & & & 200 \\
\hline $\mathrm{IN}-2$ & colza & wheat & pea & & & & & & & & IN wheat \\
\hline $\mathrm{N}$ & 600 & 590 & & & & & 270 & & 120 & & 390 \\
\hline $\mathrm{MgS}$ & 100 & & & & & & & wheat & & & 0 \\
\hline PK & & 300 & & 200 & & & & & & & 200 \\
\hline PRO - 1 & wheat & colza & wheat & & & & & & & & PRO pea \\
\hline $\mathrm{N}$ & 655 & 600 & 745 & & & & & & & & 0 \\
\hline $\mathrm{MgS}$ & & 100 & & & & & & & pea & & 0 \\
\hline PK & & & & 300 & & & & & & & 300 \\
\hline $\mathrm{PRO}-2$ & colza & wheat & pea & & & & & & & & PRO wheat \\
\hline $\mathrm{N}$ & 660 & 538 & & & & 200 & 300 & & 120 & & 620 \\
\hline $\mathrm{MgS}$ & 100 & & & & & & & wheat & & & 0 \\
\hline PK & & 300 & & 300 & & & & & & & 300 \\
\hline ORG - 1 & colza & wheat & pea & & & & & & & & ORG wheat \\
\hline Org am. & 260 & & & & & & & wheat & & & 400 \\
\hline ORG - 2 & wheat & lupin & wheat & & & & & & & & ORG pea \\
\hline Org am. & 260 & & 650 & & & & & & pea & & 0 \\
\hline
\end{tabular}

For cultivation systems: $\mathrm{IN}=$ Integrated; $\mathrm{PRO}=$ Productive; $\mathrm{ORG}=$ Organic. See Figure 1 for their place on the site. For fertilisers: (N) ammonitrate $33.5 \%$ : $\mathrm{NH}_{4} \mathrm{NO}_{3} ;(\mathrm{MgS})$ kieserit: $\mathrm{MgSO}_{4}, \mathrm{H}_{2} \mathrm{O}$; (PK) NPK 0-25-25: $\mathrm{CaHPO}_{4}, \mathrm{KCl}, 2 \mathrm{H}_{2} \mathrm{O}$.

further analyses. Six different wheat varieties (Charger, Somme, Malacca, Virtuose, Apache, Renan) and blends of them have been used for the SICS program. One variety of pea (Athos) has been cultivated. Other plants cultivated before 2000 will not be considered in the present study (Table II).

Fertilisers and amendments. Products applied in significant quantities during the last 4 years (Table II) were also randomly sampled from their commercial containers. The feather flour used in the ORG system was sampled from two different bags.

Pesticides. Pesticides were also considered as potential trace element inputs. Thirty-eight different products were used on the site during the period 1998-2002. According to commercial specifications, their active molecules are only organic and they do not contain any heavy metal (ACTA, 2001). However their exact chemical 
composition is confidential and some unmentioned additive could contain one of the studied elements. Therefore, two of them were chosen and analysed: the levels of the studied element were under the detection limit or very low (about $2 \mathrm{mg}$ $\mathrm{kg}^{-1}$ for $\mathrm{Zn}$ ). Considering the low mass input of pesticides, their applications were assumed to bring no significant amount of heavy metal into the soil.

Crops. For the purpose of SICS and other research programs, crop yields were measured. The weights of grains harvested from three or four passages of the reaping-machine on accurately measured areas of each plot provided average and standard deviations for the yields. Samples of a few kilograms of each crop were collected at the same time. Then, sub-samples were taken for the need of the present study, exactly like for seeds.

Leaching water. Humid soil $(1 \mathrm{~kg})$ was sampled at $30 \mathrm{~cm}$ depth in three locations around the centre of each plot, a few hours after a rain period. The retained procedure of soil solution extraction (centrifugation of $0.7 \mathrm{~kg}$ at $1700 \mathrm{~g}$ during 20 min) brought the soil samples to a water content of $22 \%$, corresponding to a suction of about $10 \mathrm{kPa}(\mathrm{pF} 2)$ by comparison with water retention curves obtained for the same soil horizon (D. Tessier, personal communication). So the supernatant water was assumed to be like the soil solution leaching downwards in the fields. It was then filtered (Minisart, pore diameter $0.2 \mu \mathrm{m}$ ) before analysis. Centrifugations and filtrations were done at $20^{\circ} \mathrm{C}$ but humid samples were kept in outdoor conditions until they were treated, i.e., no more than $2 \mathrm{~h}$ after field sampling.

\subsection{SAMPLE TREATMENT}

\subsubsection{Atmospheric Deposition Samples}

The collection bottle was filled before each sampling period with $50 \mathrm{~mL}$ of a $10 \%$ acidified $\left(\mathrm{HNO}_{3} 65 \%\right.$ Suprapur, Merck) Milli-Q water (18.2 $\mathrm{M} \Omega$ Milli-Q water, Millipore S.A.). This water layer allowed to dissolve particles during the sampling period. For similar reasons, at the end of each sampling period the funnel was rinsed with $100 \mathrm{~mL}$ of a $1 \%$ acidified Milli-Q water in order to collect particles deposited or adsorbed on funnel walls (Azimi et al., 2003). All this equipment was replaced by a clean one at the end of each collection period. As soon as the material was brought back to the laboratory, a $50 \mathrm{~mL}$ sub-sample of atmospheric deposition collected in the bottle and a $50 \mathrm{~mL}$ sub-sample of the rinsing water were filtered trough $0.45 \mu \mathrm{m}$ porosity membranes (Sartorius, cellulose nitrate) previously washed in a $5 \% \mathrm{HNO}_{3}$ bath. Samples were stored in a dark room at $4{ }^{\circ} \mathrm{C}$ waiting for analysis. The washing procedure of all the material necessary for samples collection and treatment is described in detail elsewhere (Azimi et al., 2003).

\subsubsection{Plant and Fertiliser Digestion}

Dry weights of crop samples were determined by heating two aliquots of them in an oven at $105^{\circ} \mathrm{C}$ during $48 \mathrm{~h}$ while fertilisers were air-dried. Without any preliminary grinding, $0.5 \mathrm{~g}$ samples was put in a Teflon vessel with $2 \mathrm{~mL} \mathrm{HNO}_{3} 65 \%$ (Prolabo 
Normapur for analysis). After $1 \mathrm{~h}$ at room temperature and pressure, $8 \mathrm{~mL}$ of ultrapure water was added, and the closed vessel was heated in a microwave-oven (MARS type, CEM corp., Matthews, NC, USA). The heating program consisted in increasing temperature up to $200^{\circ} \mathrm{C}$ during $15 \mathrm{~min}$, then keeping this temperature for $10 \mathrm{~min}$. The pressure reached about $2 \mathrm{MPa}$. The resulting solution was filtered and adjusted up to $50 \mathrm{~mL}$. Filters were rinsed with $\mathrm{HNO}_{3} 1 \%$, and all vessels were soaked overnight in $\mathrm{HNO}_{3} 10 \%$, and rinsed with pure and ultrapure water before use. Reference vegetal samples were also digested in order to validate the digestion method and the trace metal analysis. Crop and fertiliser samples were digested in replicates ( 3 and 5, respectively) and mean results were used for the flux determination.

\subsection{TRACE ELEMENT ANALYSIS}

The atmospheric depositions were analysed by Inducted Coupled Plasma (ICP-AES Perkin Elmer Optima 3000) with an ultrasonic nebuliser and an axial slit. These two devices combined together enhance the sensitivity and the detection limits for trace element analysis. Solutions obtained from crop and fertiliser sample digestions, and centrifuged soil solutions were analysed using a flame $(\mathrm{Zn})$ and furnace $(\mathrm{Cd}$, $\mathrm{Cu}, \mathrm{Ni}$ and $\mathrm{Pb}$ ) atomic absorption spectrometer (AAS Varian SpectrAA 220).

\subsection{QUALITY CONTROL}

\subsubsection{Atmospheric Sample Analysis}

A quality control has been performed using following test samples which were treated like the field samples: 1) acidified water blanks for checking the contamination during sample treatment in the laboratory; 2) acidified water blanks for checking the contamination during field collection; 3) two certified samples in trace metals presenting similar concentration and matrices as atmospheric fallout: (a) NIST 1643d: "Trace elements in water", U.S. Department of Commerce; (b) SPS-SW1 batch 105: "surface water", Spectra pure standards.

\subsubsection{Vegetal Sample Analysis}

The validation step has been performed by the analysis (after digestion when solids) of three certified samples: (a) NIST SRM 1640: "Trace Elements in Natural Water" standard reference material of National Institute of Standards and Technology (USA); (b) "Maize powder" and (c) "ground oak leaves", both certified samples of the "Unité de Service et de Recherches en Analyses Végétales et Environnementales" (USRAVE, Bordeaux, France).

\subsubsection{Analysis Validation}

Table III shows the detection limit (DL) values obtained by both ICP-AES and AAS as well as the measured values of certified samples. The DL has been deduced 
TABLE III

Detection limits (DL, $\mu \mathrm{g} . \mathrm{L}^{-1}$ ) obtained with both ICP-AES and AAS equipment and validation of analytical procedures on reference samples (mean $\pm \mathrm{SD}$ )

\begin{tabular}{|c|c|c|c|c|c|c|}
\hline & & $\mathrm{Cd}$ & $\mathrm{Cu}$ & $\mathrm{Ni}$ & $\mathrm{Pb}$ & $\mathrm{Zn}$ \\
\hline ICP DL & & 0.06 & 1.07 & 1.69 & 0.96 & 7.50 \\
\hline AAS DL & & 0.03 & 1.40 & 3.20 & 0.3 & 13 \\
\hline \multirow[t]{2}{*}{ SPS - SW1 (105) $)^{(a)}$ (Aqueous) } & $\mathrm{CV}$ & $0.50 \pm 0.01$ & $20.00 \pm 1,00$ & $10.00 \pm 0.10$ & $5.00 \pm 0.10$ & $20.00 \pm 1,00$ \\
\hline & $\mathrm{MV}(n=7)$ & $0.48 \pm 0.11$ & $17.02 \pm 0.94$ & $9.99 \pm 0.49$ & $4.83 \pm 0.36$ & $24.45 \pm 7.67$ \\
\hline \multirow[t]{2}{*}{ SRM 1643d ${ }^{(a)}$ (Aqueous) } & $\mathrm{CV}$ & $6.47 \pm 0.37$ & $20.50 \pm 3.80$ & $58.10 \pm 2.70$ & $18.15 \pm 0.64$ & $72.48 \pm 0.55$ \\
\hline & $\mathrm{MV}(n=7)$ & $7.11 \pm 0.72$ & $29.53 \pm 1.48$ & $69.25 \pm 4.78$ & $20.45 \pm 2.00$ & $82.23 \pm 6.52$ \\
\hline \multirow[t]{2}{*}{ SRM $1640^{(b)}$ (Aqueous) } & $\mathrm{CV}$ & $22.79 \pm 0.96$ & $85.20 \pm 1.20$ & $27.40 \pm 0.80$ & $27.89 \pm 0.14$ & - \\
\hline & $\mathrm{MV}(n=5)$ & $23.63 \pm 1.10$ & $92.10 \pm 21.00$ & $25.60 \pm 1.00$ & $38.46 \pm 16.17$ & - \\
\hline \multirow[t]{2}{*}{ Maize $^{(b)}$ (Solid) } & $\mathrm{RV}$ & $1.68 \pm 0.26$ & $4.72 \pm 0.54$ & $3.37 \pm 0.18$ & - & $61.19 \pm 1.39$ \\
\hline & $\mathrm{MV}(n=5)$ & $1.50 \pm 0.11$ & $4.45 \pm 0.10$ & - & $7.82 \pm 0.99$ & $58.10 \pm 3.40$ \\
\hline \multirow[t]{2}{*}{ Oak leave $^{(\mathrm{b})}$ (Solid) } & $\mathrm{RV}$ & $0.130 \pm 0.068$ & $6.78 \pm 1.36$ & $3.65 \pm 0.48$ & $2.68 \pm 0.36$ & $26.9 \pm 2.2$ \\
\hline & $\operatorname{MV}(n=14)$ & $0.10 \pm 0.03$ & $5.25 \pm 0.79$ & $3.00 \pm 0.46$ & $1.34 \pm 0.40$ & $28.5 \pm 1.73$ \\
\hline
\end{tabular}

$\mathrm{CV}=$ certified values $\left(\mu \mathrm{g} \cdot \mathrm{L}^{-1}\right) ; \mathrm{MV}=$ mean measured values for aqueous $\left(\mu \mathrm{g} \cdot \mathrm{L}^{-1}\right)$ and solid $\left(\mu \mathrm{g} \cdot \mathrm{g}^{-1}\right)$ samples; $\mathrm{RV}=$ reference values $\left(\mu \mathrm{g} \cdot \mathrm{g}^{-1}\right)$; mean measured values with either ICP-AES (a) or AAS (b). 
from the analyses of 10 blanks (acified water), by summing the mean value and three times the standard deviation of the results obtained. The relative deviations between certified or reference values and the mean measured values were below $20 \%$ in most cases. The main difference was observed for $\mathrm{Pb}$ in the NIST 1640 and oak leave samples which may be induced probably by (1) a sample pollution and (2) a matrix effect. Figure 2 shows on its left column the concentration of heavy metals $\left(\mu \mathrm{g} . \mathrm{L}^{-1}\right)$ in each TD sample. The corresponding DL was represented by an horizontal dotted line. There were only few concentration values under this limit for $\mathrm{Cu}, \mathrm{Pb}$ and $\mathrm{Zn}$. Concerning $\mathrm{Cd}$ and $\mathrm{Ni}$, some concentration values were in the same order of magnitude as the DL and some of them are even lower. However, we have used all these values for the calculation of the total deposition, even those below the detection limits.

\section{Results and Discussions}

\subsection{ATMOSPHERIC DEPOSITION}

Figure 2 presents on its right column the temporal evolution of $\mathrm{Cd}, \mathrm{Cu}, \mathrm{Ni}, \mathrm{Pb}$, and $\mathrm{Zn}\left(\mu \mathrm{g} \mathrm{m}^{-2}\right.$ per week) in bulk deposition (i.e. both dry and wet atmospheric depositions) from 1 October 2001 to 22 November 2002 at Versailles. It has to be noticed that $\mathrm{Ni}$ deposition measured for week 5 was discarded because of its very high level (330 $\mu \mathrm{g} \mathrm{m}^{-2}$ were collected during this week) which may most probably be induced by a sample contamination. Nevertheless, there is a tendency for deposition to be low when precipitation volumes were high while high deposition occurred during dry periods. These deposition peaks were mainly noticed four times in the $\mathrm{Ni}$ case (week 13, 26, 37 and 45), three times for $\mathrm{Cd}, \mathrm{Cu}$ and $\mathrm{Zn}$ (weeks 24, 25 and 44; week 37, 41 and 44 and week 24, 26 and 44, respectively) and twice for $\mathrm{Pb}$ (week 24 and 43). It is also noteworthy that the deposition of none of the five elements appeared to be correlated with the amount of precipitation. Indeed, atmospheric deposition processes occurring during dry weather periods are an important and even prevalent contribution to total atmospheric deposition (Azimi et al., 2003; Sweet et al., 1998). Consequently, low metal concentrations with high volume precipitation samples arise from the dilution of dry deposition during rain events. The total annual depositions $\left(\mathrm{g} \mathrm{km}^{-2}\right.$ per year) were calculated aggregating weekly depositions for each element (Table IV). Uncertainties were estimated taking into account the uncertainty on weekly values, mostly resulting from standard deviation of triplicate analyses. Results showed the predominance of $\mathrm{Zn}$ which was more than four times higher than the other elements in atmospheric depositions which were ranked as $\mathrm{Cu}>\mathrm{Pb}>\mathrm{Ni}>\mathrm{Cd}$. Such a global pattern was already observed at a similar urban site in the east side of the Paris area. Indeed, a previous research program (Azimi et al., 2003) measured depositions of 335, 9700, 9450 and $15000 \mathrm{~g} \mathrm{~km}^{-2}$ per year for $\mathrm{Cd}, \mathrm{Cu}, \mathrm{Pb}$ and $\mathrm{Zn}$, respectively, during the year 2001. Nevertheless, heavy metal depositions seem to be lower at the Versailles 


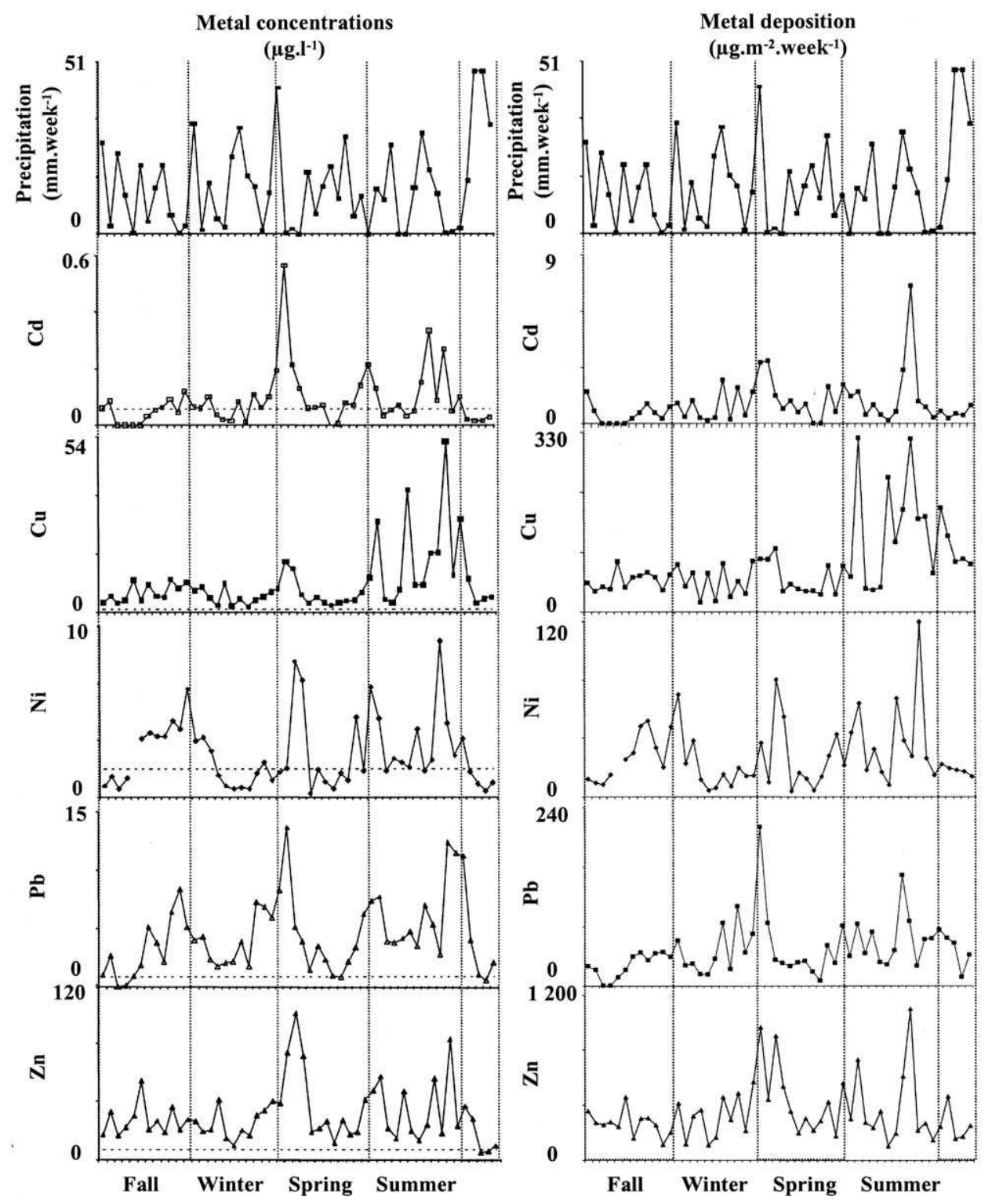

Figure 2. Weekly evolution in heavy metal concentrations $\left(\mu \mathrm{g} \mathrm{L}^{-1}\right.$, left column $)$ and total atmospheric depositions ( $\mu \mathrm{g} \mathrm{m}^{-2}$ per week, right column) from October 2001 to November 2002 at Versailles. The doted horizontal line on the left column indicates the detection limit for each metal. Upper graphs on both columns represent weekly evolution of precipitation ( $\mathrm{mm}$ per week).

site which is located at the west side of Paris. Such decrease may probably be induced by the lower impact of the Paris area since the global air mass flow of this region is mainly from the west to the east (Garban et al., 2002). The Ni deposition was also in the same order of magnitude as measured by other studies performed in 
TABLE IV

Annual atmospheric deposition of heavy metal $\left(\mathrm{g} \mathrm{km}^{-2}\right.$ per year) aggregating weekly deposition values. The uncertainty is assessed by aggregating the uncertainty of each week determination step

\begin{tabular}{lllll}
\hline $\mathrm{Cd}$ & $\mathrm{Cu}$ & $\mathrm{Ni}$ & $\mathrm{Pb}$ & $\mathrm{Zn}$ \\
\hline $47 \pm 5$ & $3900 \pm 415$ & $1500 \pm 140$ & $2200 \pm 230$ & $15600 \pm 1600$ \\
\hline
\end{tabular}

urbanised locations. Indeed Lawlor and Tipping (2003) found values ranging from 300 to $1200 \mathrm{~g} \mathrm{~km}^{-2}$ per year for Ni in Northern England and Kim et al. (2000) found 800 and $1100 \mathrm{~g} \mathrm{~km}^{-2}$ per year at Chesapeake and Delaware Bay, USA.

\subsection{OTHER FLUXES OF HEAVY METALS THROUGH THE EXPERIMENTAL PLOTS}

\subsubsection{Fertilisers and Amendments}

Mass flows. Table II presents a summary of operations during 4 years, with more details on application periods along the crop year 2002, i.e., from September 2001 to July 2002. Since the different cultivation systems are defined by different sets of decision rules rather than by a definite experience procedure, applications of fertilisers and crops vary with time. The only stated option is to cultivate wheat every two years in all systems. In order to present the influence of cultivation systems and crops on heavy metal fluxes, annual mass flows of the different fertilisers were considered for each association system/crop (wheat or pea) under definite pedoclimatic conditions, i.e., on a definite plot during 2002. The sum of two annual fluxes in the same field allowed us to compare the different systems without referring to a particular crop.

Heavy metal contents of fertilisers and corresponding input fluxes. Table $\mathrm{V}$ presents results of chemical analyses of all agricultural products applied on experimental plots during the period 1998-2002, except the organic amendment used up in 1999. From these contents and from mass flows given in Table II, the input fluxes of $\mathrm{Cd}, \mathrm{Cu}, \mathrm{Ni}, \mathrm{Pb}$, and $\mathrm{Zn}$ in plots cultivated could be deduced following the three systems with wheat or pea. Contrary to crops, no attempt was made to assess the uncertainty on the rates of applied fertilisers. So the uncertainty on inputs from fertilisers was estimated only from analytical results reported in Table $V$ and the following formula (Frontier et al., 2001). Knowing that the input of each metal is calculated with:

$$
F=a X+b Y,
$$

where $X$ and $Y$ are the metal contents of different fertilisers, and $a$ and $b$ are the rates of their application, the variance of (1) is given by:

$$
V(F)=a^{2} V(X)+b^{2} V(Y)
$$


TABLE V

Concentrations $\left(\mathrm{mg} \mathrm{kg}^{-1}\right)$ and annual loads $\left(\mathrm{g} \mathrm{km}^{-2}\right.$ per year) of heavy metals in agricultural inputs (fertilisers)

\begin{tabular}{llllll}
\hline & $\mathrm{Cd}$ & $\mathrm{Cu}$ & $\mathrm{Ni}$ & $\mathrm{Pb}$ & $\mathrm{Zn}$ \\
\hline Heavy metal contents & & & & & \\
$\mathrm{N}(n=1)$ & 0.03 & 3.6 & $<1$ & $<2$ & 7.2 \\
$\mathrm{MgSO}_{4}(n=5)$ & $0.15 \pm 0.03$ & $0.95 \pm 0.16$ & $40.6 \pm 0.8$ & $0.9 \pm 0.2$ & $6.9 \pm 1.3$ \\
PK $(n=5)$ & $10.3 \pm 1.2$ & $18.3 \pm 0.7$ & $9.8 \pm 0.3$ & $5.9 \pm 0.2$ & $87 \pm 1.7$ \\
Feather flour $(n=3)$ & $1.02 \pm 0.16$ & $1.95 \pm 0.05$ & $2.3 \pm 0.2$ & $1.79 \pm 0.35$ & $120 \pm 4$ \\
Wheat & & & & & \\
PRO & $311 \pm 36$ & $772 \pm 37$ & $325 \pm 32$ & $239 \pm 62$ & $3056 \pm 106$ \\
IN & $207 \pm 24$ & $506 \pm 24$ & $216 \pm 20$ & $157 \pm 39$ & $2020 \pm 68$ \\
ORG & $41 \pm 6$ & $78 \pm 2$ & $92 \pm 8$ & $72 \pm 14$ & $4800 \pm 160$ \\
Pea & & & & & \\
PRO & $309 \pm 36$ & $549 \pm 21$ & $294 \pm 9$ & $177 \pm 6$ & $2610 \pm 51$ \\
IN & $206 \pm 24$ & $366 \pm 14$ & $196 \pm 6$ & $118 \pm 4$ & $1740 \pm 34$ \\
ORG & 0 & 0 & 0 & 0 & 0 \\
\hline
\end{tabular}

Uncertainty for heavy metal content corresponds to standard deviation of analysis. For cultivation systems: IN = Integrated; PRO = Productive; $\mathrm{ORG}=$ Organic. See Figure 1 for their place on the site. For fertilisers: (N) ammonitrate 33.5\%: $\mathrm{NH}_{4} \mathrm{NO}_{3}$; (MgS) kieserit: $\mathrm{MgSO}_{4} \cdot \mathrm{H}_{2} \mathrm{O}$; (PK) NPK 0-25-25: $\mathrm{CaHPO}_{4} \cdot \mathrm{KCl} \cdot 2 \mathrm{H}_{2} \mathrm{O}$.

and the uncertainty on annual inputs is calculated as:

$$
\sigma(F)=\sqrt{\left(a^{2} \sigma^{2}(X)+b^{2} \sigma^{2}(Y)\right)},
$$

where $V(X)$ and $V(Y)$ represent the variances of $X$ and $Y$, and $\sigma$ the standard deviation.

The contents of $\mathrm{Ni}$ and $\mathrm{Pb}$ in the $\mathrm{N}$ fertiliser are low in a range close to the blank values. But the high application load of $\mathrm{N}$ on wheat in PRO and IN systems may induce a significant contribution of this fertiliser. Indeed differences between inputs of metal on wheat and pea (Table V) are due to this application. In the Pb case, it may represent about $40 \%$ of the metal input on wheat, considering the upper plausible limit of the 'ammonitrate' $\mathrm{Pb}$ content (Table $\mathrm{V}$ ). The $\mathrm{N}$ fertiliser also carries about $30 \%$ of the input of $\mathrm{Cu}$ in PRO and IN systems on wheat. Its contribution to $\mathrm{Ni}$ and $\mathrm{Zn}$ input loads lies between $10 \%$ and $20 \%$ and it is negligible for $\mathrm{Cd}$. For this latter element, inputs are mainly due to the PK-fertiliser, applied on both crops in PRO and IN systems. However, PK fertilisation also induces significant input fluxes of $\mathrm{Cu}, \mathrm{Ni}, \mathrm{Pb}$, and $\mathrm{Zn}$.

The organic amendment carried significant amounts of $\mathrm{Ni}, \mathrm{Pb}$, and mostly $\mathrm{Zn}$, into the ORG system on wheat. The inputs of heavy metals in organic agriculture 
from the authorized amendments and fertilisers may clearly vary with their origin and quality. $\mathrm{MgSO}_{4}$ fertiliser was not used on fields in 2002, but it can be seen from Tables II and V that it induced a major input of $\mathrm{Ni}$ in fields cultivated with colza in PRO and IN systems.

Finally, among agricultural inputs, seeds have been analysed for their heavy metal contents. The calculated input fluxes were very low, so they were neglected in the rest of the study.

\subsubsection{Crops}

All crop varieties of wheat and pea from the different systems were analysed with three replicates. Concerning wheat, no significant differences were observed between varieties (two values for $\mathrm{Cd}$ and two values for $\mathrm{Pb}$ were considered as non significant and rejected). The statistical tests only showed that the average content of $\mathrm{Zn}$ in ORG wheat samples was significantly different from the corresponding overall average. Therefore, results are distinguished for ORG and other wheat grains. Means and standard deviations were obtained from 20 results for the wheat grown in PRO and IN systems, from six analyses for ORG wheat, and from 12 analyses for pea (Table VI). Table VI also presents crop yields obtained in 2001. The cultivated plots were homogeneous for pea, whereas up to six different varieties of wheat were cultivated in IN and ORG systems. However, since no significant variations of heavy metal contents were observed within each system, calculations were done

\section{TABLE VI}

Heavy metal contents $\left(\mu \mathrm{g} \mathrm{g}^{-1}\right)$, yield $\left(\mathrm{kg} \mathrm{m}^{-2}\right.$ per year) and output fluxes $\left(\mathrm{g} \mathrm{km}^{-2}\right.$ per year) in crops

\begin{tabular}{|c|c|c|c|c|c|c|}
\hline & Yield & $\mathrm{Cd}$ & $\mathrm{Cu}$ & $\mathrm{Ni}$ & $\mathrm{Pb}$ & $\mathrm{Zn}$ \\
\hline \multicolumn{7}{|l|}{ Crop } \\
\hline $\begin{array}{l}\text { Wheat (no ORG) } \\
\qquad(n=20)\end{array}$ & & $0.036 \pm 0.016$ & $3.25 \pm 0.88$ & $<0.3$ & $<0.03$ & $19.6 \pm 2.0$ \\
\hline $\begin{array}{l}\text { Wheat (ORG) } \\
\quad(n=6)\end{array}$ & & $0.046 \pm 0.013$ & $5.16 \pm 1.02$ & $<0.3$ & $<0.03$ & $33.1 \pm 2.4$ \\
\hline Pea $(n=12)$ & & $0.007 \pm 0.0001$ & $6.66 \pm 0.63$ & $1.09 \pm 0.17$ & $<0.03$ & $30.6 \pm 2.5$ \\
\hline \multicolumn{7}{|l|}{ Wheat } \\
\hline PRO & $1.01 \pm 0.01$ & $36.0 \pm 16.0$ & $3279 \pm 904$ & $<303$ & $<30$ & $19776 \pm 2116$ \\
\hline IN & $0.61 \pm 0.07$ & $22.0 \pm 12.0$ & $1966 \pm 747$ & $<181$ & $<18$ & $11858 \pm 2504$ \\
\hline ORG & $0.13 \pm 0.04$ & $6.1 \pm 3.8$ & $681 \pm 367$ & $<40$ & $<4$ & $4369 \pm 1806$ \\
\hline \multicolumn{7}{|l|}{ Pea } \\
\hline PRO & $0.32 \pm 0.08$ & $2.2 \pm 0.8$ & $2131 \pm 680$ & $349 \pm 130$ & $<9.6$ & $9790 \pm 3000$ \\
\hline IN & $0.22 \pm 0.04$ & $1.6 \pm 0.5$ & $1492 \pm 390$ & $244 \pm 80$ & $<6.7$ & $6854 \pm 1723$ \\
\hline ORG & $0.27 \pm 0.02$ & $1.9 \pm 0.4$ & $1792 \pm 275$ & $293 \pm 61$ & $<8.1$ & $8230 \pm 1160$ \\
\hline
\end{tabular}

For cultivation systems: IN = Integrated; $P R O=$ Productive; $O R G=$ Organic. See Figure 1 for their place on the site. 
with the yield mean values, and the standard deviations were considered to assess the uncertainties on yields. Consequently, the output fluxes of heavy metals induced by harvesting were calculated (Table VI) and the uncertainties were calculated taking into account both uncertainties, from the chemical analyses and from the yields. $\mathrm{Ni}$ and $\mathrm{Pb}$ contents in grains were generally under $\mathrm{DL}$ values, thus outputs of $\mathrm{Pb}$ due to crops are very low. The fluxes are low for $\mathrm{Cd}$ and $\mathrm{Ni}$, and rather high for $\mathrm{Cu}$ and $\mathrm{Zn}$. Except for Cd, output fluxes from the ORG system were higher with pea cultures than with wheat. Considering wheat, large variations between the different systems also occurred, which are due, above all, to large differences in yields.

\subsubsection{Leaching}

Samples of leaching water were collected from March to May 2002. In April and May, volumes of soil solution samples obtained by centrifugation were less than a few millilitres, and actually, the water flow estimated by the CERES model was nil during this period. Therefore, analytical results were obtained only for samples collected in March, which were used to calculate the heavy metal fluxes for the whole year. Whatever plot considered, the calculated annual amount of leached water was about the same, despite the different crop yields. Indeed, no or little drainage was found from April to October, when crops covered fields. The calculated annual drainage was $240 \pm 5 \mathrm{~mm}$ for all plots.

Differences between concentrations for one element in the different systems were generally lower than the variations observed within a particular plot (three replicates). Therefore, a mean value $(n=24)$, or an overvalue (when concentration was below DL), was adopted for each element in all plots and the corresponding fluxes have been calculated (Table VII). No value could be obtained for zinc because water sample volumes were not sufficient for flame AAS analysis. The flow of water leached from the $0-30 \mathrm{~cm}$ layer has been considered known with more accuracy than its composition. So uncertainties on heavy metal fluxes were estimated from chemical data only. The relatively high uncertainties for $\mathrm{Cd}$ and $\mathrm{Pb}$ compared to the DL values, are mainly due to the dispersion of analytical results for waters extracted from soil samples, and partly to the levels of blanks. Results found for $\mathrm{Ni}$ were significantly above blank values, although they were close to the DL values.

TABLE VII

Heavy metal concentrations $\left(\mu \mathrm{g} \mathrm{L}^{-1}\right)$ in soil water $(\mathrm{mean} \pm \mathrm{SD})$ and estimated annual drainage fluxes $\left(\mathrm{g} \mathrm{km}^{-2}\right.$ per year) at $30 \mathrm{~cm}$ depth

\begin{tabular}{llllll}
\hline & $\mathrm{Cd}$ & $\mathrm{Cu}$ & $\mathrm{Ni}$ & $\mathrm{Pb}$ & $\mathrm{Zn}$ \\
\hline \multirow{2}{*}{ Concentrations } & $n=9$ & $n=23$ & $n=23$ & $n=23$ & - \\
Fluxes & $0.2 \pm 0.2$ & $13.7 \pm 2.0$ & $2.4 \pm 0.7$ & $<5$ & n.a. \\
\hline
\end{tabular}

n.a.: not available. 
The leaching of $\mathrm{Cu}$ has been quantified with more accuracy, and seemed to be relatively important (see below).

\subsection{HEAVy METAL FLUXES AND BALANCES IN THE DIFFERENT PLOTS AND CULTIVATION SYSTEMS}

Figures 3 and 4 present the inputs (grey arrows), the outputs (white arrows) and the balance of $\mathrm{Cd}, \mathrm{Cu}, \mathrm{Ni}$ and $\mathrm{Pb}$ for each system and each crop. Atmospheric depositions were the main inputs of $\mathrm{Cu}, \mathrm{Ni}$ and $\mathrm{Pb}$, whatever the system and the crop considered. Indeed, except for $\mathrm{Cd}$ and for pea in the ORG system, the atmospheric inputs were 5 to 50 times higher than the agricultural ones. On the contrary, agricultural inputs of $\mathrm{Cd}$ were higher than atmospheric inputs by a factor 6 and 4 in PRO and IN systems, respectively. In the ORG system, wheat fields received the same inputs of $\mathrm{Cd}$ from fertilisation and atmospheric deposition, while pea received no agricultural inputs at all.

The outputs were lower than inputs in most cases. Indeed, whatever the system and the crop considered, an accumulation of $\mathrm{Ni}$ and $\mathrm{Pb}$ appeared in the cultivated soil, with a balance comprised between 630 and $1200 \mathrm{~g} \mathrm{~km}^{-2}$ per year. However, the high uncertainty on $\mathrm{Pb}$ leaching has to be pointed out, and it could allow for a net balance of more than $2000 \mathrm{~g} \mathrm{~km}^{-2}$ per year of $\mathrm{Pb}$. The accumulations of $\mathrm{Cd}$ present larger variations with cropping systems, lying between 39 and $279 \mathrm{~g} \mathrm{~km}^{-2}$ per year for wheat, and between 2 and 311 for pea. In the case of $\mathrm{Cu}$, an essential nutriment, the crop uptake and the leaching were high, so the balance was negative, ranging from -512 to $-1900 \mathrm{~g} \mathrm{~km}^{-2}$ per year, except for wheat in the ORG system where the fluxes were practically balanced.

To assess the significance of these fluxes, the annual balance determined for each element must be compared to the stock of the same element in the cultivated horizon. This stock was calculated from the heavy metal contents shown in Table I or, for $\mathrm{Cu}$ and $\mathrm{Ni}$, obtained by Juste and Tauzin (1986) in neighbouring plots, and from the rough estimation of $4 \times 10^{8} \mathrm{~kg} \mathrm{~km}^{-2}$ of soil in the cultivated horizon. The annual balances of $\mathrm{Cd}, \mathrm{Cu}, \mathrm{Ni}$, and $\mathrm{Pb}$, reached $0.33,-0.024,0.014$ and $0.014 \%$, respectively, of their total amounts in this horizon. Therefore, the present accumulation rate of $\mathrm{Cd}$ may significantly change the $\mathrm{Cd}$ content of a surface horizon at the time scale of a century (mainly in the PRO system). The other elements should accumulate, or deplete in the case of $\mathrm{Cu}$, much more slowly. However, only a fraction of these heavy metals is available for plants and organisms. Then, for a better assessment, the determination of the annual variation of the total stock should be completed by an estimation of the variation of the available fraction for each studied element (Coïc and Coppenet, 1989; Juste and Mench, 1992).

The comparison of the different cultivation systems allowed a better understanding of heavy metal accumulation in the cultivated horizon. Knowing that the ORG systems do not receive any PK fertiliser, the heavy metal accumulation is weaker than in other systems for $\mathrm{Cd}$, and to a lesser extent for $\mathrm{Ni}$ and $\mathrm{Pb}$. Concerning $\mathrm{Cu}$, 

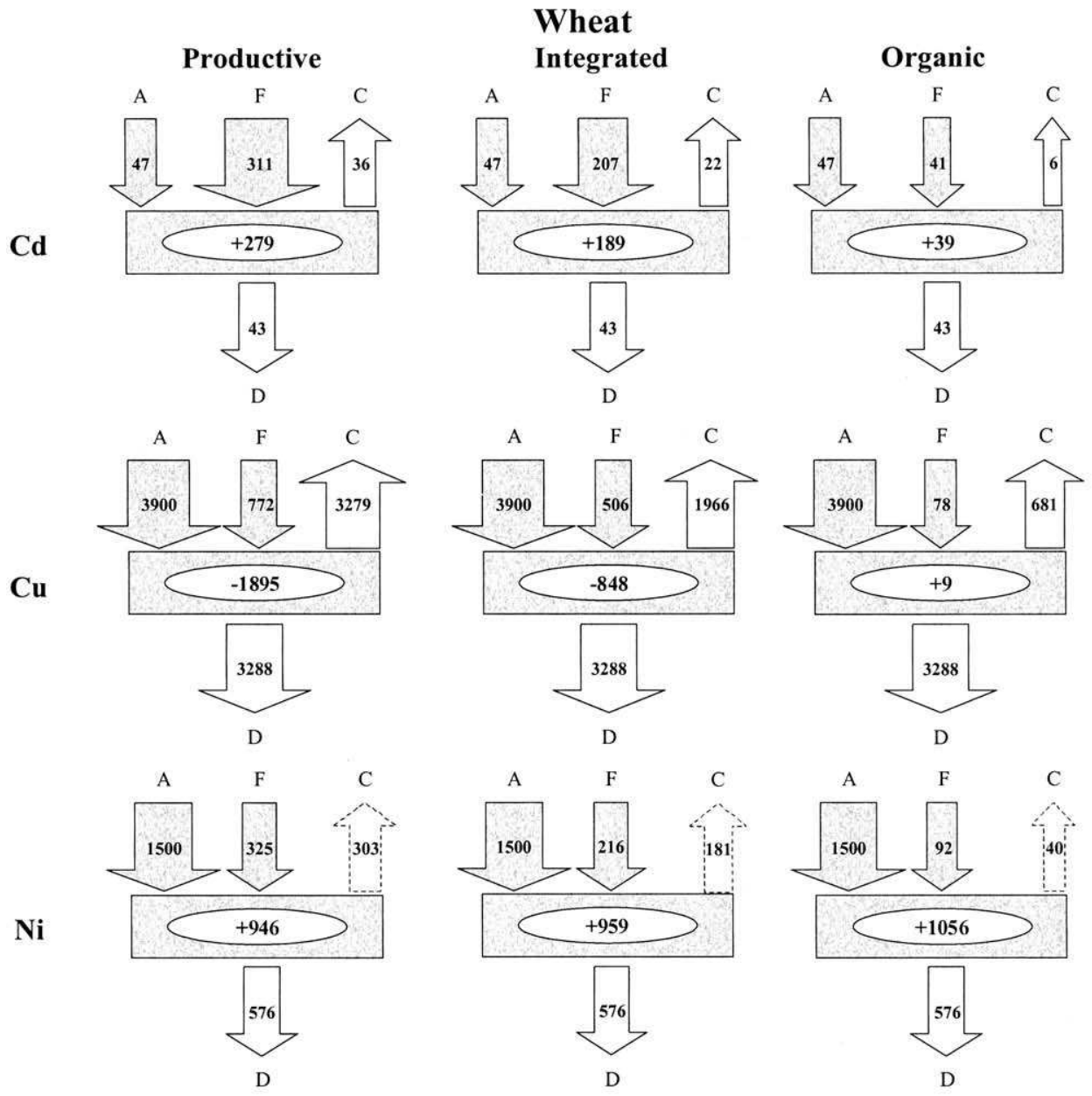

$\mathbf{P b}$
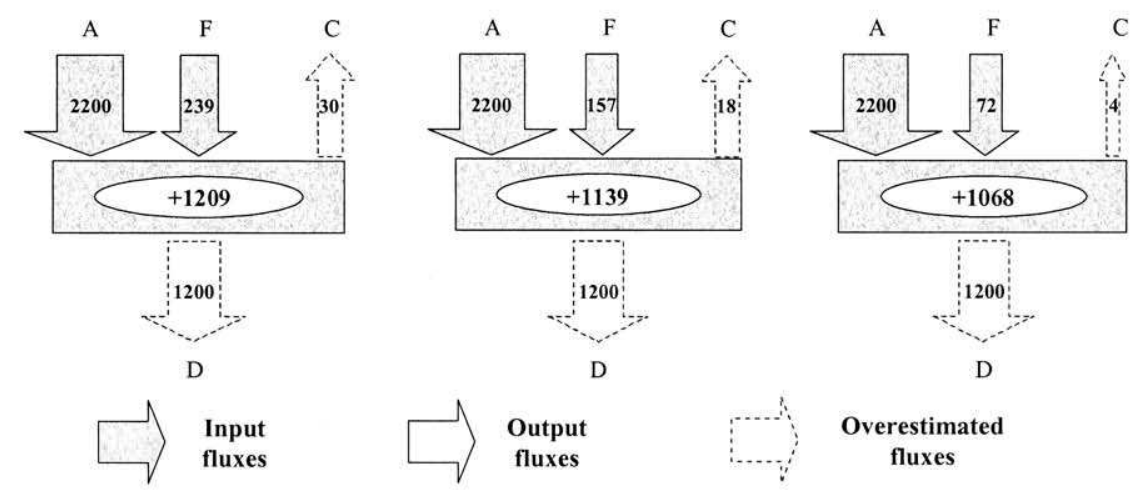

Overestimated fluxes

Figure 3. Annual balance $\left(\mathrm{g} \mathrm{km}^{-2}\right.$ per year) of heavy metal fluxes in soil in the case of wheat culture under the three cultivation systems (A: atmospheric depositions, F: fertilisers, C: crops, D: drainage water). 
Pea

Productive
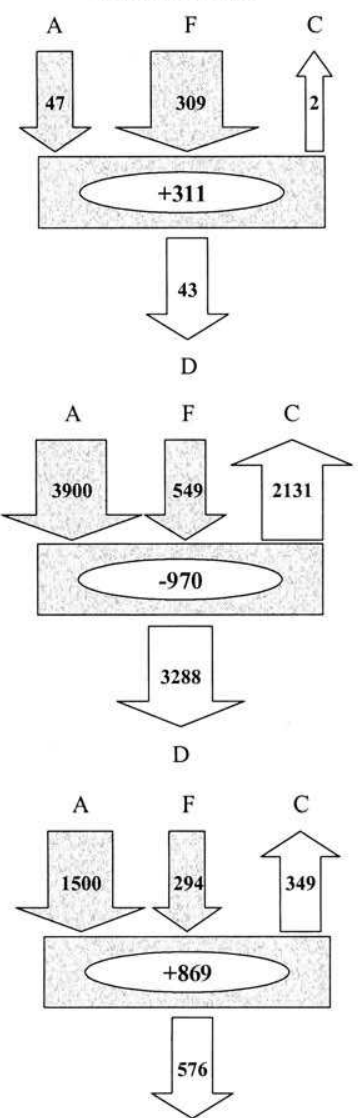

D

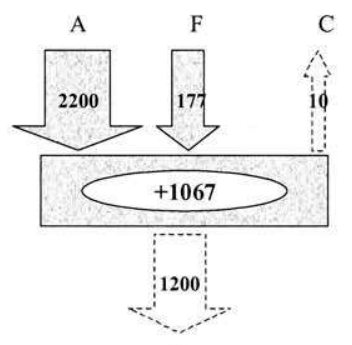

$\mathrm{D}$
Integrated

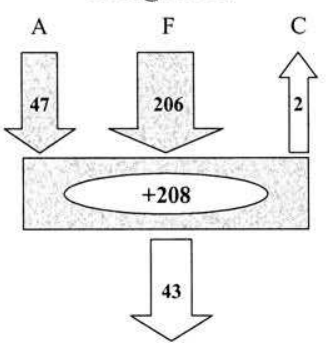

D

Organic

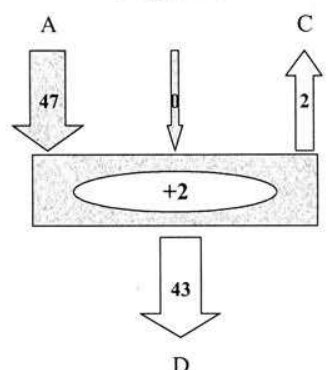

D

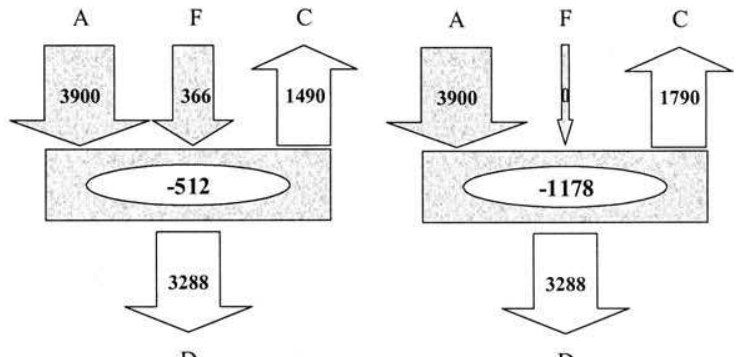

D
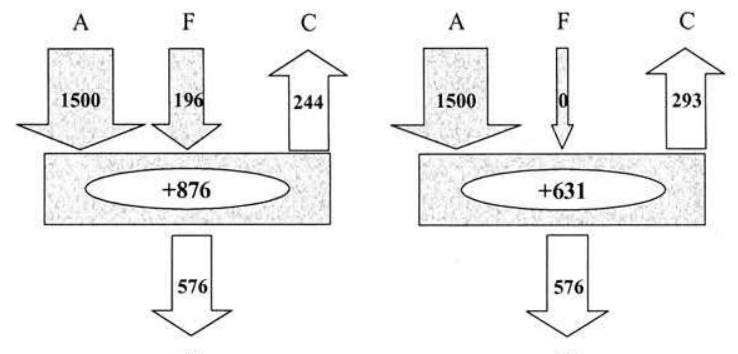

D

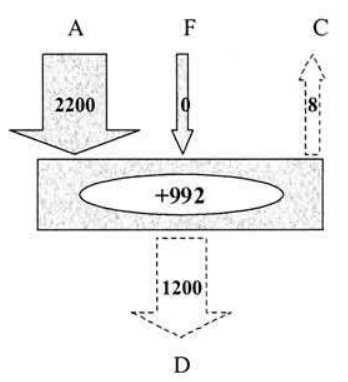

Overestimated fluxes

Figure 4. Annual balance $\left(\mathrm{g} \mathrm{km}^{-2}\right.$ per year) of heavy metal fluxes in soil in the case of pea culture under the three cultivation systems (A: atmospheric depositions, F: fertilisers, C: crops, D: drainage water). 
the high yield for both wheat and pea productive system induces high output fluxes for copper, which may lead to a copper depletion in the soil.

\section{Conclusions}

The present work assessed the annual balance and fluxes of $\mathrm{Cd}, \mathrm{Cu}, \mathrm{Ni}, \mathrm{Pb}$ and $\mathrm{Zn}$, in agrosystems of Northern France. Although the studied area was experimental fields not far from urban areas inducing an anthropogenic influence, the large surfaces and the cultivation history make them representative for wheat-pea rotations on soils which are little or not contaminated. To estimate the balances throughout the soil, two input and two output fluxes were determined.

Both input fluxes were determined with enough accuracy, the main difficulty arising from the large load of nitrogen fertiliser in productive system with $\mathrm{Pb}$ and $\mathrm{Ni}$ contents close to the analytical detection limit. The determination of output fluxes also faced low contents of $\mathrm{Cd}, \mathrm{Pb}$ and $\mathrm{Ni}$ in crop grains and in soil water. The comparison of different cultivation systems, with organic farming avoiding PK mineral fertiliser, pointed out the effect of this product on $\mathrm{Cd}$ accumulation in soils. For the other elements, atmospheric depositions remain the main source of heavy metals to these fields in 2002. All the studied element trends are to accumulate in the cultivated horizons, except $\mathrm{Cu}$ which is depleted by intensive crops. On the other hand, the annual net balances are much lower that the present stocks of elements.

\section{Acknowledgements}

The authors gratefully acknowledge the financial support from French Agency for Environment (ADEME) and from EDF (Electricité de France), as well as the collaboration of P. Saulas, B. Gabrielle, A. Jaulin and D. Cetaku from INRA.

\section{References}

ACTA: 2001, Index phytosanitaire, Association de Coordination Technique Agricole, Paris, 724 pp.

Azimi, S., Ludwig, A., Thévenot, D.R. and Colin, J.-L.: 2003, 'Trace metal determination in total atmospheric deposition in rural and urban areas', Sci. Total Environ. 308, 247-256.

Barber, S.A.: 1995, Soil Nutriment Bioavailability, A Mechanistic Approach, John Wiley \& sons, New York, $414 \mathrm{pp}$.

Bartl, B., Hartl, W. and Horak, O.: 2002, 'Long-term application of biowaste compost versus mineral fertilisation: effects on the nutrient and heavy metal contents of soil and plants', J. Plant Nutr. Soil Sci. 165, 161-165.

Brus, D. J., De Gruijter, J. J., Walvoort, D. J. J., De Vries, F., Bronswijk, J. B. B., Römkens, P. F. A. M. and De Vries, W.: 2002, 'Mapping the probability of exceeding critical thresholds for cadmium concentrations in soils in the Netherlands', J. Environ. Quality 31, 1875-1884.

Coïc, Y. and Coppenet, M.: 1989, Les oligoéléments en agriculture et en élevage, INRA, Paris, 114 pp. 
De Vries, W. and Bakker, D. J.: 1996, 'Manual for Calculating Critical Loads of Heavy Metals for Soils and Surface Waters', DLO report 114, Wageningen, NL, 173 pp.

Frontier, S., Davoult, D., Gentilhomme, V. and Lagadeuc, Y.: 2001, Statistiques pour les sciences de la vie et de l'environnement, Dunod, Paris, $377 \mathrm{pp}$.

Gabrielle, B., Menasseri, S. and Houot, S.: 1995, 'Analysis and field evaluation of the ceres models water balance component', Soil Sci. Soc. Am. J. 59, 1403-1412.

Garban, B., Blanchoud, H., Motelay-Massei, A., Chevreuil, M. and Ollivon, D.: 2002, 'Atmospheric bulk deposition of PAHs onto France: trends from urban to remote sites', Atmos. Environ. 36, 5395-5403.

Hovmand, M. F.: 1984, 'Cycling of Pb, Cd, Cu, Zn and Ni in Danish agriculture', in Berlung Davis and Hermite (eds.), Commission of the European Communities, Utilisation of Sewage Sludge on Land: Rates of Application and Long-Term Effects of Metals, Reidel, Dordrecht, The NetherLands, pp. $166-185$

Jones, C. A. and Kiniry, J. R.: 1986, Ceres-N Maize: A Simulation Model of Maize Growth and Development, Texas A\&M University Press, College station, TX.

Jones, K. C., Symon, C. J. and Johnston, A. E.: 1987, 'Retrospective analysis of an archive soil collection. i. metals', Sci. Total Environ. 61, 131-144.

Jones, K. C., Symon, C. J. and Jonhston, A. E.: 1987, 'Retrospective analysis of an archive soil collection. ii. cadmium', Sci. Total Environ. 67, 75-89.

Juste, C. and Mench, M.: 1992, 'Long term application of sewage sludge and its effects on metal uptake by crops', in D.C Adriano (ed.), Biogeochemistry of Trace Elements, Lewis, Boca Raton, FL, USA, pp. 159-193.

Juste, C. and Robert, M.: 2000, 'Les apports et les sources de contaminations en traces', C.R. Acad. Agric. FR. 86, 13-24.

Juste, C. and Tauzin, J.: 1986, 'Evolution du contenu en métaux lourds d'un sol de limon maintenu en jachère nue après 57 années d'application continue de divers engrais et amendements', C.R. Acad. Agric. FR. 9, 739-746.

Keller, A., Steiger, B., Van der Zee, S. E. A. T. M. and Schulin, R.: 2001, 'A stochastic empirical model for regional heavy metal balances in agroecosystems', J. Environ. Quality 30, 1976-1989.

Kim, G., Scudlark, J. R. and Church, T. M.: 2000, 'Atmospheric wet deposition of trace elements to Chesapeake and Delaware Bays', Atmos. Environ. 34, 3437-3444.

Lawlor, A. J. and Tipping, E.: 2003, 'Metals in bulk deposition and surface waters at two upland locations in Northern England', Environ. Pollut. 121, 153-167.

Lobinski, R.: 1995, 'Organolead compounds in archives of environmental pollution', Analyst 120, 615-621.

Mench, M.: 1998, 'Cadmium availability to plants in relation to major long term changes in agronomic systems', Agrosys. Ecosys. Environ. 67, 175-187.

Moolenaar, S. W. and Lexmond, T. M.: 1998, 'Heavy metal balances of agro-ecosystems in the Netherlands', Netherlands J. Agric. Sci. 46, 171-192.

Sweet, C. W., Weiss, A. and Vermette, S. J.: 1998, 'Atmospheric deposition of trace metals at three sites near the Great Lakes', Water Air Soil Pollut. 103, 423-439.

Weiss, D., Shotyk, W., Appleby, P. G., Kramers, J. D. and Cheburkin, A. K.: 1999, 'Atmospheric $\mathrm{Pb}$ deposition since the industrial revolution recorded by five swiss peat profiles: enrichment factors, fluxes, isotopic composition and sources', Environ. Sci. Technol. 33, 1340-1352. 